Edward T. Crosby 8Sc MD FRCPC, Stephen $\mathrm{H}$. Halpern MD FRCPC

\title{
Obstetric epidural anaesthesia in patients with Harrington instrumentation
}

This five-year retrospective study reviews our experience with epidural obstetric analgesia in patients with previous Harrington rod instrumentation (HRI) for correction of idiopathic scoliosis. Patients were identified by the presence of an antepartum anaesthetic consuliation for HRI. The anaesthetic record was examined to determine the frequency of epidural catheter insertion and any problems related to this procedure. Nine epidural insertions were attempted in the 16 patients identified. Five were uncomplicated but four were complicated by ane or more of: failure to identify the epidural space, blood vessel trauma, dural puncture, failure to obtain analgesia or the need for multiple attempts before successful insertion. There were no sequelae related to epidural insertion. There were no sequelae related to epidural insertion. We conclude that patients with HRI may be offered epidural anaesthesia for labour and delivery provided that they are informed of the increased risk of complications.

\section{Key words}

ANAESTHESIA: obstetrical; ANAESTHETIC TECHNIQUES: epidural; sURGERY: orthopaedic, Harrington rods; COMPLICATIONS: scoliosis.

Department of Anaesthesia, Women's College Hospital, University of Toronto, 76 Grenville Street, Toronto, Ontario, M5S 1B2.

Address Correspondence to: Dr. E.T. Crosby.
Scoliosis is a rotational deformity of the spine and ribs. If untreated there is an increase in deformity over time with increasing functional impairment. Over the past 25 years, early Harrington (rod) instrumentation has been used to prevent the natural progression of the disease. ${ }^{\prime}$

Patients with surgically corrected scoliosis present in the labour and delivery suite with increasing frequency. Unfortunately there is little in the anaesthetic literature concerning obstetrical analgesia and anaesthesia in these patients. We report our experience with 14 parturients with previous Harrington instrumentation who presented to the obstetrical anaesthesia service.

\section{Methods}

Following institutional approval and using our obstetrical consultation service records as a guide, the charts of all patients presenting for labour and delivery between January, 1983 and December, 1988 with a history of Harrington instrumentation were reviewed. The interval since spinal surgery as well as medical and back-related problems were noted. The course of the pregnancy was reviewed regarding new onset of problems, particularly in relation to the spine and the cardiopulmonary systems.

The anaesthetic record was examined to determine the mode of analgesia offered, the use of epidural analgesia and the problems encountered. Finally the outcome of the labour with respect to spontaneous, assisted or operative delivery was noted.

\section{Results}

Sixteen obstetrical patients with a history of Harrington instrumentation for correction of idiopathic scoliosis were seen in consultation by the obstetrical anaesthesia service. Two patients delivered their babies elsewhere and no further information is available regarding their labour and delivery. In eight patients, epidural analgesia was attempted and one patient received an epidural on two occasions. The details of those nine cases are presented in the Table. Three patients chose general anaesthesia for elective Caesarean section and three declined regional anaesthesia for labour or delivery.

All patients were cared for by experienced anaesthe- 
TABLE Case details-obstetric epidural anaesthesia for patients with Harrington rods

\begin{tabular}{|c|c|c|c|c|c|c|c|c|c|c|}
\hline \multirow[b]{2}{*}{ Pt. } & \multirow[b]{2}{*}{ Age } & \multirow[b]{2}{*}{ Parity } & \multirow[b]{2}{*}{$G A^{*}$} & \multirow{2}{*}{$\begin{array}{l}\text { Inlerval } \\
\text { since fusion }\end{array}$} & \multirow{2}{*}{$\begin{array}{l}\text { Segments } \\
\text { fused }\end{array}$} & \multirow{2}{*}{$\begin{array}{l}\text { Back } \\
\text { symptoms }\end{array}$} & \multicolumn{3}{|c|}{ Epidural anaesthesia } & \multirow[b]{2}{*}{ Outcome } \\
\hline & & & & & & & Attempted & Complications & Analgesia & \\
\hline 1 & 32 & 1 & 38 & 16 years & $\mathrm{T}_{?}-\mathrm{L}_{2}$ & none & $\mathrm{L}_{3-4}$ & none & satisfactory & midforceps \\
\hline 2 & 40 & 0 & 35 & remote & $\mathrm{T}_{4}-\mathrm{L}_{\mathrm{I}}$ & $\begin{array}{l}\text { chronic } \\
\text { back pain }\end{array}$ & $L_{2-3}$ & $\begin{array}{l}\text { shallow poorly } \\
\text { defined space }\end{array}$ & satisfactory & midforceps \\
\hline 3 & 36 & 0 & 34 & 24 years & $\mathrm{T}_{\eta}-\mathrm{L}_{2}$ & none & $\begin{array}{l}L_{3-4} \\
L_{2-3}\end{array}$ & $\begin{array}{l}\text { blood in cath } \\
\text { none }\end{array}$ & satisfactory & Caesarean \\
\hline 4 & 23 & 0 & 41 & 12 years & $\mathrm{T}_{4}-\mathrm{L}_{2}$ & none & $\begin{array}{l}\mathrm{L}_{3-4} \\
\mathrm{~L}_{2-3}\end{array}$ & $\begin{array}{l}\text { unsuccessful } \\
\text { mult attempts }\end{array}$ & satisfactory & Caesarean \\
\hline 5 & 30 & 0 & 40 & 17 years & $T_{5}-L_{3}$ & none & $\begin{array}{l}L_{3-4} \\
L_{4-5}\end{array}$ & $\begin{array}{l}\text { unsuccessful } \\
\text { unsuccessful }\end{array}$ & none & low forceps \\
\hline 6 & 38 & 0 & 38 & 25 years & $T_{?}-L_{1}$ & $\begin{array}{l}\text { chronic } \\
\text { back pain }\end{array}$ & $\mathrm{L}_{3-4}$ & ineffective & & \\
\hline 7 & 24 & 2 & 40 & 12 years & $\mathbf{T}_{\eta}-\mathbf{L}_{2}$ & none & $\begin{array}{l}\mathrm{L}_{3-4} \\
\mathrm{~L}_{4-5}\end{array}$ & $\begin{array}{l}\text { dural puncture } \\
\text { none }\end{array}$ & $\begin{array}{l}\text { none } \\
\text { satisfactory }\end{array}$ & $\begin{array}{l}\text { low forceps } \\
\text { Caesarean }\end{array}$ \\
\hline $8 a$ & 26 & 0 & 41 & 13 years & $\mathbf{T}_{7}-\mathbf{L}_{3}$ & none & $\mathrm{L}_{3-4}$ & none & satisfactory & low forceps \\
\hline $8 b$ & 28 & I & 39 & 15 years & $\mathbf{T}_{7}-\mathbf{L}_{\mathbf{3}}$ & none & $\mathrm{L}_{3-4}$ & none & satisfactory & $\begin{array}{c}\text { spontaneous } \\
\text { vaginal }\end{array}$ \\
\hline
\end{tabular}

*GA - gestational age

tists. Five of the nine epidural catheter insertions were noted to be uncomplicated and successful on the first attempt although in one patient the space was felt to be "shallow and poorly defined." Four of the nine insertions were complicated. The complicated insertions involved multiple attempts prior to successful insertion, blood in the catheter requiring a second insertion, an ineffective epidural with a dural puncture on a repeated attempt and an inability to define the epidural space despite attempts at two levels. There were no sequelae related to the epidural insertion.

Of the nine labours in patients who received epidural analgesia only one concluded with a spontaneous vaginal delivery. Three patients underwent Caesarean section, two babies were delivered with midforceps and three were delivered with low forceps applications. Two of the three patients who declined regional anaesthesia for labour achieved spontaneous vaginal delivery and one was delivered by low forceps.

Seven patients who had successful catheter insertion obtained satisfactory analgesia. Adequate analgesia was obtained with volumes of local anaesthetic in keeping with normal epidural catheter function. One patient had a catheter placed without difficulty but no block resulted (\#6). The dura was punctured on a repeated attempt and no further attempts at insertion were made. The patient did not develop a dural puncture headache. The three patients with epidural catheters who were delivered by caesarean section and the two delivered with midforceps application achieved satisfactory surgical anaesthesia without a requirement for adjunct agents. The three patients who declined regional anaesthesia and the two in whom an epidural catheter could not be inserted were managed with a combination of inhalational analgesia and local infiltration for labour and delivery.

\section{Discussion}

The incidence of scoliosis in the North American population is four per $1000 .^{2}$ Scoliosis is usually idiopathic and occurs seven times more frequently in females than males. ${ }^{3}$ Other less common causes of scoliosis include vertebral anomalies, neurological disorders such as cerebral palsy, polio or neurofibromatosis, myopathic disorders such as myotonic dystrophy and muscular dystrophy, connective tissue disorders such as Marfan's syndrome and rheumatoid arthritis and, infection, especially tuberculosis. The severity of the scoliosis is determined by measurement of the angle of the spinal curve. The natural history of the untreated severe curve is progression of the deformity over time resulting in early death from cardiorespiratory failure. ${ }^{2}$

In 1962 Harrington published his series of patients with structural scoliosis treated by curve correction and internal fixation by spinal instrumentation. ${ }^{4}$ During Harrington instrumentation, the spinal musculature is reflected off the vertebrae over the course of the curve and hooks are attached at the upper and lower extremes. After the spinous processes and interspinous ligaments have been removed, an outrigger assembly is attached to these hooks, on the concave side of the curve. The spine is then extended, correcting the curve. The vertebrae are decorticated throughout the extent of the planned fusion. The 
Harrington rod is inserted into the hooks, replacing the outrigger assembly, and extended maximally. Along the convex side of the curve a compression system of hooks and threaded rods may be added. Bone graft material is obtained from the ilium and placed over the decorticated vertebrae. Following the correction, the patient undergoes a variable period of casting and immobilization to allow for maturation of the bone graft.

Two additional techniques of spine instrumentation have been developed. In the Luque technique, two L-shaped rods are secured in place with sublaminar wires. The Luque rods apply transverse forces along the spine to achieve curve correction. ${ }^{5}$ The Cofrel-Dubousset technique involves the use of a rod system that combines the distraction-compression forces of the Harrington technique with the strength of the Luque segmentation technique. ${ }^{6}$ The advantage of these two newer techniques is that there is rarely a need for postoperative casting and immobilization. All three techniques involve spinal instrumentation and extensive bone grafting in the axial spine.

Follow-up studies of patients who underwent early operative correction of severe scoliotic curves demonstrated significant increases in lung volumes postoperatively. ${ }^{7,8}$ Delaying correction until adulthood appears to reduce the gains that can be made in lung function, when compared with earlier correction. ${ }^{9}$ Follow-up studies of patients who underwent early instrumentation demonstrate them to be free of the cardiopulmonary complications that afflict patients with severe uncorrected disease. , $^{17-10}$

Pregnancy may exacerbate both the severity of spinal curvature and the cardiorespiratory abnormalities in patients with uncorrected scoliosis. ${ }^{2,11}$ Maternal morbidity and mortality correlates well with the degree of functional impairment present before pregnancy. ${ }^{11} \mathrm{~Pa}$ tients with corrected scoliosis tolerate pregnancy, labour and delivery well, although studies have demonstrated an increased incidence of operative delivery when compared with normal parturients.' A Caesarean section rate 2.4 times expected has been observed in patients with corrected scoliosis. In our series, five of the thirteen labours, 38 per cent, ended either with Caesarean section or midforceps delivery.

Previous spinal surgery is felt, by some, to represent a relative contraindication to the use of regional anaesthesia. Consideration must be given to the following potential problems: (1) persistent back pain may occur in 41 per cent of patients with corrected scoliosis and correlates with both increasing age of the patient at follow-up and increasing extent of fusion; $;^{1,9}$ (ii) degenerative changes occur in the spine below the area of fusion at a rate greater than that seen in nonscoliotic patients and both retrolisthesis and spondylothesis are increased; ${ }^{9}$ (iii) although there is increasing emphasis on limiting the number of lumbar segments involved in the fusion, 20 per cent of patients in some studies are fused to $\mathrm{L}_{4}$ and $\mathrm{L}_{5}$ levels; ${ }^{12}$ (iv) insertion of an epidural needle through either the midline or lateral approach in the fused area is not possible because of the presence of both scar tissue and bone graft material ${ }^{13}(v)$ the ligamentum flavum may be injured during surgery resulting in adhesions in the epidural space or obliteration of the epidural space and this may interfere with spread of local anaesthetic injected into the epidural space $^{14}$ (vi) obliteration of the epidural space may increase the incidence of dural puncture and it may not be possible to provide an epidural blood patch should significant postdural puncture headache result; (vii) the incidence of malignant hyperthermia may be increased in patients with both idiopathic scoliosis or with neuromyopathic syndromes that predispose to scoliosis ${ }^{2}$ and, finally; (viii) these patients often manifest a high degree of anxiety about their backs and may be reluctant to have an epidural catheter inserted.

All of our patients were seen in antepartum consultation. None had neurological problems or restrictive pulmonary disease. Two of them had chronic back pain and one had an exacerbation of her symptoms during the pregnancy. The potential problems with epidural anaesthesia were discussed with all the patients. Roentgenograms of the spine were not available for all patients but we felt that we were able to assess adequately the lower extent of fusion on the basis of history, physical examination, and previous $x$-ray reports. We did not order $x$-rays on any patients seen in consultation.

Our patients experienced a higher degree of complications related to epidural anaesthesia than we expected. Only five of nine patients had the catheter inserted without complications on the first attempt. This, despite the fact that all epidural catheter insertions were attempted by experienced anaesthetists who each perform approximately 200 obstetric epidurals per year.

Previous reports have described the use of obstetric epidural anaesthesia in two patients with Harrington rods, ${ }^{13}$ one patient with extensive spinal fusion for kyphoscoliosis $^{13}$ and a patient with a Meureig Williams plate $\left(\mathrm{L}_{1}-\mathrm{L}_{4}\right)$, inserted after a traumatic injury to the lumbar spine. ${ }^{15}$ All the epidural catheters were inserted without complications and a satisfactory block developed in the four patients. However, another report described a high incidence of difficulties encountered during the insertion of epidural catheters in these patients. ${ }^{16}$ Hubbert, in a letter, described attempting epidural anaesthesia in 17 parturients with Harrington rods in situ. ${ }^{16}$ In five patients with fusions ending above $\mathrm{L}_{3-4}$, four insertions were successful and one was abandoned after repeated blood in the needles. In 12 patients with fusions extending 
to the $\mathrm{L}_{\mathrm{S}}-\mathrm{S}_{\mathrm{I}}$ interspace, six were unsuccessful, five required multiple attempts through defects in the fusion mass and in one patient, a dural tap resulted after multiple attempts at epidural insertion. False loss of resistance was a recurring problem during the attempted epidurals. In one of our patients (Patient 6) a false loss of resistance similar to that described by Hubbert was encountered. No block resulted after the injection of local anaesthetic

Incomplete analgesia due to a patchy block is cited as being a potential complication in parturients with previous back trauma or injury. ${ }^{14}$ Schachner has suggested that this may be due to epidural adhesions and scarring that may develop during healing following disc injury. Epidurography performed in their pain clinic demonstrated failure of contrast material to diffuse past the level of an injured disc, exiting the foramina below the abnormal disc. A similar phenomenon may occur in patients with previous spinal instrumentation. The ligamentum flavum may be stripped, disrupted or compressed into the epidural space during placement of the lower hook at the time of instrumentation. During the healing process the epidural space may be partially or totally obliterated. The spread of local anaesthetic injected into such an epidural space may be hampered and a patchy block may result.

In summary, we recommend that parturients who have undergone Harrington instrumentation for scoliosis be seen in antepartum anaesthetic consultation. At that time, the spine may be assessed and modes of analgesia and anaesthesia for labour and delivery may be discussed. The patients should be made aware of the potential problems with epidural anaesthesia at this time. These patients may be offered epidural anaesthesia for labour and delivery. An increased incidence of complications and failure to obtain satisfactory analgesia can be anticipated.

\section{Acknowledgement}

The authors would like to thank Yolanda Lum for her assistance in preparing this manuscript.

\section{References}

1 Cochran T, Irstam L, Nachemson A. Long term anatomic and functional changes in patients with adolescent idiopathic scoliosis treated by Harrington rod fusion. Spine 1983; 8: 576-84.

$2 \mathrm{Kafer} E R$. Respiratory and cardiovascular function in scoliosis and the principles of anesthetic management. Anesthesiology 1980; 52: 339-51.

3 Keim HA. Scoliosis. Clin Symp 1979; 31: 2-30.

4 Harrington PR. Treatment of scoliosis. J Bone Joint Surg 1962; 44A: 591-610.
5 Wengner $D R$, Carollo $J$, Wilkerson $J A$. Biomechanics of scoliotic correction by segmental spinal instrumentation. Spine 1982; 7: 260-4.

6 The latest wrinkle in correcting scoliosis. Am J Nurs, 1985; 85: 13.

7 Gazioglu K, Goldstein LA, Femi-Pearse D, Yu PN. Pulmonary function in idiopathic scoliosis. Comparative evaluation before and after orthopaedic correction. J Bone Joint Surg 1968; 50A: 1391-9.

8 Lindh $M$, Bjure J. Lung volumes in scoliosis before and after correction by the Harrington instrumentation method. Acta Orthop Scand 1975; 46: 934-48

9 Sponseller PD, Cohen MS, Nachemson AL, Hall JE, Wohl $M E B$. Results of surgical treatment of adults with idiopathic scoliosis. J Bone Joint Surg 1987; 69A: 667-75.

10 Moskowitz A, Moe $J H$, Winter RB, Binner H. Long-term followup of scoliosis fusion. J Bone Joint Surg 1980; 62A: $364-76$.

11 Eisenach JC. Orthopaedic disease. In: Obstetric Anaesthesia: The complicated patient. 2nd ed. James FM, Wheeler AS, Dewan DM (Eds.). Philadelphia: F.A. Davis, 1988, 234-6.

12 Aaro $S$, Ohlen $G$. The effect of Harrington instrumentation on the saggital mobility of the spine in scoliosis. Spine 1983; 8: 570-5.

13 Feldstein $G$, Ramanathan S. Obstetrical lumbar epidural anesthesia in patients with previous posterior spinal fusion for kyphoscoliosis. Anesth Analg 1985; 64: 83-5.

14 Schachner SM, Abram SE. Use of two epidural catheters to provide analgesia of unblocked segments in a patient with lumbar disc disease. Anesthesiology 1982; 56: 150-1.

15 Walpole JB. Continuous lumbar epidural block in labour in the presence of a Meureig Williams plate from $\mathrm{L}_{1}-\mathrm{L}_{4}$. Br J Anaesth 1974; 46: 163-4.

$16 \mathrm{Hubbert} \mathrm{CH}$. Epidural anesthesia in patients with spinal fusion. Anesth Analg 1985; $64: 843$.

Résumé

Cette êtude rétrospective revoit notre expérience d'une anaigésie épidurale en obstétrique chez des patientes ayant précédemment subi une opération de Harrington. Neuf insertions de catherer épidural furent tentes chez 16 patientes. Cinq furent sans complication et quatre furent compliqués par une ou plusieurs des complications suivantes : impossibilité d' identifier l'espace épidural, trauma des vaisseaux sanguins, ponction de la dure-mère, impossibilité d'obtenir de l'analgesie ou plusieurs tentatives afin d' insérer le cathéter. On conclut que les patientes ayant HRI peuvent subir une anesthésie épidurale lors du travail et de l'accouchement en autant qu'elles soient informées du risque croissant de complications. 